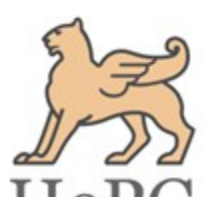

\title{
Antimicrobial activity of leaf and root methanolic extracts from Vinca pusilla Murr.
}

\author{
Gireesh M. Ankad, Harsha D. Pedmekar, Sandeep R. Pai, Harsha V. Hegde, Subarna Roy, \\ and S.L. Hoti
}

Regional Medical Research Centre, ICMR, Nehru Nagar, Belagavi, Karnataka, India

\section{Article history}

Received: 22 September 2015

Accepted: 23 October 2015

Published online: 1 January 2016

(C) Ankad et al. (2016)

Editor

K. K. Sabu

Publisher

Horizon e-Publishing Group

Corresponding Author

Harsha V. Hegde

$\triangle$ drhvhegde@gmail.com

\begin{abstract}
Vinca pusilla Murr. is a traditional medicinal plant used to treat several diseases. To substantiate the traditional medicinal utility of the plant, the present study aims at screening the antimicrobial activity of methanolic extracts of leaves and roots against five Gram positive, five Gram negative bacterial and four fungal strains. The minimum inhibitory concentration (MIC) were determined by two fold dilution assay. The results indicated that, leaf and root extracts were more effective on Bacillus subtilis and Staphylococcus aureus strains (MIC $<1 \mathrm{mg} / \mathrm{mL}$ ). The tested organisms were sensitive to root extract compared to leaf extract. Fungal strains were resistant than the bacterial strains to both the extracts. Thus the present study illustrates the antimicrobial potential of the plant.
\end{abstract}

\section{Keywords}

Vinca pusilla; traditional medicine; methanolic extract; antimicrobial; Bacillus subtilis; Staphylococcus aureus

Ankad, G. M., Pednekar, H. D., Pai, S. R., Hegde, H. V., Roy, S. and Hoti, S.L. 2016. Antimicrobial activity of leaf and root methanolic extracts from Vinca pusilla Murr. Plant Science Today 3(1): 6-8. http://dx.doi.org/10.14719/pst.2016.3.1.163

\section{Introduction}

Vinca pusilla Murr. Syn. Catharanthus pusillus (Murr.) G. Don, (Family: Apocynaceae) also known as 'Tiny Periwinkle' is an erect annual herb (Yadav, 2002). The genus Catharanthus comprises of 8 species, all originating from Madagascar except $C$. pusillus, which is restricted to India and Sri Lanka (Schmelzer and Gurib-Fakim, 2008). Traditionally the roots, leaves and latex of the plant are widely used to treat various conditions like skin and liver diseases, leprosy, dysentery, worms, ulcers, tumor and to relieve ear ache. (Subbaiyan, 2013).

Ethanolic extracts of $C$. pusillus possesses hypoglycaemic and anti-diabetic activities (Navitha, 2012). It is reported to contain good number of oncolytic alkaloids (Debjani, 1992). So far, at least 74 alkaloids have been isolated from the genus Catharanthus. Sixty six of these have been isolated from $C$. roseus, 21 from C. lanceus, 5 from C. pusillus, and one from C. trichophyllus (Kim, 1970). Subbaiyan et al., 2014, identified the major compounds by Gas chromatography and mass spectrum (GC-MS) method in aerial parts of $C$. pusillus.

Antibiotic resistance has become a global concern and emergence of multidrug resistant pathogens are increasing at an alarming rate. Further, there is an increase in failure due to drugs. Hence, initiatives to screen several medicinal plants for their antimicrobial activity has been emphasized (Cushnie and Lamb, 2005). Plants, especially with ethnomedicinal claims, have attracted the scientific community to evaluate their complete range of biological activities starting from antibiotic to antitumor activities. The potential of these plants as source for new drugs largely remain unexplored till date. As estimated out of 500,000 plant species, only a small percentage has been investigated for their biological or pharmacological activity (Ankad et al., 2013). Since olden days, humans have used herbs to treat infectious diseases and some of these traditional medicines are still included as a part of treatment in various ailments. Presently, inability of synthetic drugs to treat many 
Table 1. Comparative activities of extracts with standards

\begin{tabular}{lccc}
\hline \multirow{2}{*}{ Microbial strains } & \multicolumn{2}{c}{ Vinca pusillus } & Standard \\
\cline { 2 - 4 } & Leaf & Root & $0.012 \pm 0.005$ \\
M. luteus & $1.67 \pm 0.59^{* *}$ & $1.13 \pm 0.54^{*}$ & $0.012 \pm 0.005$ \\
B. subidermidis & $1.04 \pm 0.29^{* *}$ & $0.67 \pm 0.37^{*}$ & $0.015 \pm 0.005$ \\
M. flavus & $0.52 \pm 0.15^{* *}$ & $0.33 \pm 0.19^{\mathrm{n}}$ & $0.009 \pm 0.000$ \\
S. aureus & $1.67 \pm 0.59^{* *}$ & $1.13 \pm 0.54^{*}$ & $0.015 \pm 0.005$ \\
K. pneumoniae & $0.83 \pm 0.29^{* *}$ & $0.56 \pm 0.27^{*}$ & $0.019 \pm 0.000$ \\
$P$. aeruginosa & $4.17 \pm 1.18^{* *}$ & $2.67 \pm 1.49^{*}$ & $0.009 \pm 0.000$ \\
S. typhimurium & $2.08 \pm 0.59^{* *}$ & $1.34 \pm 0.75^{*}$ & $0.019 \pm 0.000$ \\
E. aerogenes & $2.67 \pm 1.49^{*}$ & $2.50 \pm 0.00^{*}$ & $0.012 \pm 0.005$ \\
E. coli & $2.50 \pm 0.00^{* *}$ & $2.08 \pm 0.59^{* *}$ & $0.012 \pm 0.005$ \\
A. niger & $3.33 \pm 1.18^{* *}$ & $2.26 \pm 1.08^{*}$ & $0.032 \pm 0.009$ \\
A. fumigatus & $5.00 \pm 0.00^{* *}$ & $4.17 \pm 1.18^{* *}$ & $0.039 \pm 0.000$ \\
A. flavus & $5.00 \pm 0.00^{* *}$ & $4.17 \pm 1.18^{* *}$ & $0.052 \pm 0.018$ \\
$P$. chrysogenum & $4.17 \pm 1.18^{* *}$ & $4.17 \pm 1.18^{* *}$ & $0.065 \pm 0.018$ \\
\hline
\end{tabular}

Values in table indicated mean MIC values \pm SD in $\mathrm{mg} / \mathrm{mL}$. Standard: Streptomycin - bacteria; Fluconazole - fungi

** $\mathrm{P}<0.01, * \mathrm{P}<0.05,{ }^{\mathrm{ns}} \mathrm{P}>0.05$

communicable and chronic diseases has resulted in paradigm shift of efforts in search for herbs or natural products with therapeutic properties. The exercise of screening antimicrobial activities of plants has already provided modern medicine with an abundance of drugs and treatments against the infectious diseases (Ankad et al., 2014). Hence, the present study aims at screening of methanolic extracts of leaf and roots of Vinca pusilla for their antimicrobial activity.

\section{Materials and methods \\ Plant materials and chemicals}

Plant materials of Vinca pusilla were obtained from a single population at Belagavi, (N 15.88 ${ }^{\circ}$; E $74.52^{\circ}$, $801 \mathrm{M}$ above MSL) Karnataka state, India. The specimen was authenticated and deposited at Herbarium, Regional Medical Research Centre, Belagavi (Voucher Number: RMRC 658).

\section{Extraction}

Leaves and roots collected were shade dried and coarsely powdered in a pulverizer. The powders were extracted by cold maceration using methanol and the extracts obtained were concentrated under reduced pressure at $40^{\circ} \mathrm{C}$ using rotary evaporator (Heidolf, Germany). The obtained leaf and root residual extracts were stored at $4^{\circ} \mathrm{C}$ until further use.

\section{Antimicrobial activity}

\section{Microbial strains}

The selected microbial strains, Micrococcus luteus (NCIM 2871), Staphylococcus epidermidis (NCIM 2493), Bacillus subtilis (NCIM 2063), Micrococcus flavus (NCIM 2376), Staphylococcus aureus (NCIM 2079), Escherichia coli (NCIM 2574), Klebsiella pneumoniae (NCIM 2957), Pseudomonas aeruginosa (NCIM 5029), Salmonella typhimurium (NCIM 2501), Enterobacter aerogenes (NCIM 5139) and fungal strains, Aspergillus niger (NCIM 620), Aspergillus flavus (NCIM 544), Aspergillus fumigatus (NCIM 902) and Penicillium chrysogenum (NCIM 733) were procured from National Collection of Industrial Microorganisms (NCIM), Pune, India.

\section{Preparation of test samples and standards}

The leaf and root extracts were dissolved in $10 \%$ Dimethyl sulfoxide (DMSO). The inocula were prepared in nutrient broth after incubating for 18 to 24 hours at $37^{\circ} \mathrm{C}$, the suspensions were adjusted to 0.5 McFarland standard turbidity (McFarland, 1987).

\section{Tube dilution method}

Antimicrobial activity was compared against streptomycin and fluconazole as positive reference standards for bacterial and fungal strains respectively. Two-fold tube dilution method was followed as explained by Ankad et al., 2013 to determine the Minimum Inhibitory Concentration (MIC) of leaf and root extracts against mentioned microorganisms.

The concentrations of both extracts were $10 \mathrm{mg} / \mathrm{mL}$, serial two fold dilution was made ranging from 10 to 0.019 $\mathrm{mg} / \mathrm{mL}$. $5 \mathrm{Mg} / \mathrm{mL}$ of streptomycin and fluconazole were dissolved in sterile distilled water and serial two fold dilutions were prepared ranging from 5 to $0.009 \mathrm{mg} / \mathrm{mL}$. Tubes were incubated for 24 and 48 hours for bacteria and fungi respectively at $37^{\circ} \mathrm{C}$. MIC was determined as the lowest concentration that inhibited visible growth of microorganisms. Experiments were replicated thrice $(n=3)$ with mean \pm SD.

\section{Statistical analysis}

Statistical analysis was conducted using Graphpad. Analysis of variance (ANOVA) was done by repeated measures analysis of variance (Tukey-Kramer multiple comparisons tests). All determinations were done at least in triplicate and average results were mentioned.

\section{Results and Diseussion \\ Antimicrobial activity}


Antimicrobial activity tested were obtained as MIC $(\mathrm{mg} / \mathrm{mL})$. The experiment was carried out using streptomycin and fluconazole $(5 \mathrm{mg} / \mathrm{mL})$ as standards and the comparative activities of extracts with standards are summarized in Table 1.

Both extracts inhibited the growth of organisms with varying degree of MIC confirming antimicrobial property. Among Gram +ve bacteria, B. subtilis and S. aureus were the most susceptible organisms with MIC values $<1 \mathrm{mg} / \mathrm{mL}$ in both leaf and root methanolic extracts. Similarly, among Gram-ve bacteria, $P$. aeruginosa was more effectively inhibited by root extract with MIC value $1.34 \pm 0.75$ $\mathrm{mg} / \mathrm{mL}$, while other bacteria were inhibited by extracts with higher MIC values (> $2 \mathrm{mg} / \mathrm{mL}$ ). Fungal strains were more resistant to both extracts with MIC values $>2.5 \mathrm{mg} / \mathrm{mL}$. Over all, root extract was more effective than leaf extract on all tested organisms.

Test organisms used for antimicrobial assay have been responsible for diseases such as diarrhea, urinary tract infection, wounds and sepsis etc. (Ankad, 2014). Traditionally, the roots, leaves and latex of $V$. pusilla are used to treat skin and liver diseases, leprosy, dysentery, worms, ulcers, tumor and ear ache (Subbaiyan et al., 2013). The results of the present antimicrobial activity of $V$. pusilla based on its traditional usage is in accordance with the results of Subbaiyan et al. (2013), where the study revealed the antibacterial activity of methanol extracts of whole plant on gram +ve and -ve organisms by disc diffusion method. The study conducted by Subbaiyan et al. (2014) suggests that antimicrobial potential of $C$. pusillus may be due to the presence of major compounds identified in aerial parts such as Pregn-16-en-20-one, 11,18-bis (acetyloxy)-3,9-epoxy-3methoxy-, (3à,5á,11à)-(15.60\%), 9-Octadecenoic acid (14.03\%), 3-Methyl-trans-2,3-epoxycyclohexan-1ol(8.53\%), 1H-Purin-6-amine, [(2-fluorophenyl)methyl], (7.47\%), Octadecanoic acid (6\%). In roots, stigmasterol (13.26\%), ç-Sitosterol (11.39\%), 2, 5-Dimethoxy-4ethylamphetamine (4.68\%).

Govindasamy et al. (2012) reported, the ethanolic and methanolic extracts of the other species, $V$. rosea shown better results against $S$. typhi, the results are in contrary to the present study, wherein $V$. pusilla yielded better activity against $B$. subtilis and $S$. aureus

Further studies on activity guided fractionation are essential to identify the active fractions and compounds responsible for the activity. Such screenings for the traditional usages of the plants for different ailments may lead to new phyto remedies for the global application, based on the local traditional knowledge.

\section{Competing Interests:}

The authors do not have any competing interests

\section{Author's contribution:}

GMA has contributed in collection of plant, processing of plant material, extraction process, designing the antimicrobial assay, preparation of manuscript and data analysis. HDP has contributed in literature survey, extraction of plant material and antimicrobial assay. SRP has contributed in collection and identification of plant, extraction of plant material and preparation of manuscript. $\mathrm{HVH}$ has contributed in guiding and designing the study, identification of plant, preparation and finalizing the manuscript and analysis of data and communicating the manuscript. SR and SLH have monitored the antimicrobial activity and contributed in preparation and correction of the manuscript.

\section{Acknowledgements}

Authors are indebted to the Indian Council of Medical Research (ICMR) for funding the study through the intramural funds of Regional Medical Research Centre, Belagavi. Authors are thankful to Mr. Venkatesh A. Millanatti, and Mr. Jotiba B. Palekar Lab Attendants, RMRC Belgaum, for their assistance during the study.

\section{References}

Abraham, J., and Dennis, T. T. 2012. Antibacterial activity of medicinal plant Cyclea peltata (Lam) Hooks \& Thoms. Asian Pac J Trop Dis. 2(4): 280-284. doi: 10.1016/s22221808(12)60166-2.

Ankad, G. M., Upadhya, V., Pai, S. R., Roy, S. R. and Hegde, H. V. 2014. Comparative Screening of Biological Activities and Polyphenol Content in Extracts and Essential Oils of Chloroxylon swietenia DC. Proc. Natl. Acad. Sci., India, Sect. B Biol. Sci. doi: 10.1007/s40011-014-0468-7.

Ankad, G., Upadhya, V., Pai, S. R., Hegde, H. V., and Roy S. 2013. In vitro antimicrobial activity of Achyranthes coynei Sant. Asian Pac J Trop Dis. 3(3): 192-195. doi: 10.1016/s22221808(13)60039-0.

Debjani, B. 1992. Effects of Growth Retardant on Growth, Flowering and Alkaloid Production in Catharanthus pusillus. Indian Forester. 118(9): 659-661.

Govindasamy, C., and Srinivasan R. 2012. In vitro antibacterial activity and phytochemical analysis of Catharanthus roseus (Linn.) G. Don. Asian Pacific Journal of Tropical Biomedicine. S155-S158

Kim, H. K., Blomster, R. N., Fong, H. H. S. and Farnsworth, N. R. 1970. The Isolation of Tetrahydroalstonine, Vindorosine, and Ursolic Acid from C. trichophyllus. Economic Botany. 24(1): 42-46. doi: 10.1007/bf02860633.

Mc Farland, J. 1987. Standardization of bacterial culture for disc diffusion assay. J Am Med Assoc. 49: 1176- 1178.

Navitha, A., Helen Sheeba, D. A., Ramesh, C., and Sartaj Banu M. 2012. Hypoglycemic and anti-diabetic activity of ethanolic extract of Catharanthus pusillus (Murray) G. Don. IOSR Journal of Pharmacy. 2(4): 17-21. doi: 10.9790/301324401721 .

Schmelzer, G. H., and Gurib-Fakim, A. 2008. Plant Resources of Tropical Africa I, In: Medicinal plants. Ed. PROTA Foundation, Wageningen Netherlands/ Backhuys. Publishers, Leiden, Netherlands /CTA, Wageningen., Netherlands, p 152-159.

Subbaiyan, B., Samydurai P., KarthikPrabu, M., and Thangapandian V. 2014. Gas chromatography and mass spectrum analysis of Catharanthus pusillus (Murray) g. Don (Apocyanaceae). Int. Res J Pharm. App Sci. 4(2): 4852.

Subbaiyan, B., Samydurai, P., KarthikPrabu, M., Ramakrishnan, R., and Thangapandian, V. 2013. Physico-phytochemical analysis and antibacterial prospective of Catharanthus pusillus (Murray) G. Don an important anticancer medicinal plant. Int J Pharm Pharm Sci. 5(2): 212-215.

Tim-Cushnie, T. P. and Lamb, J. A. 2005. Antimicrobial activity of flavonoids. Int J Antimicrobial Agents. 26(5): 343-356. doi: 10.1016/j.ijantimicag.2005.09.002.

Yadav, S. R. and Sardesai, M. M. 2002. Systematic treatment. In: Flora of Kolhapur district. Shivaji University., Kolhapur, India. p. 276. 